http://jmscr.igmpublication.org/home/ ISSN (e)-2347-176x ISSN (p) 2455-0450 crossref DOI: https://dx.doi.org/10.18535/jmscr/v8i10.38

\author{
Journal Of Medical Science And Clinical Research \\ IGM Publication \\ An Official Publication of IGM Publication
}

\title{
Fenofibrate: An Underused Drug in Treatment of ARDS in COVID-19
}

\author{
Authors \\ Dr Sidhartha Sankar Bhuyan ${ }^{1}$, Dr Rakesh Mohanty ${ }^{2}$, Dr Swayamprava Sasmal ${ }^{3}$ \\ ${ }^{1}$ Junior Resident, Department of Internal Medicine, VIMSAR, Burla \\ ${ }^{2}$ Junior Resident, Department of Internal Medicine, VIMSAR, Burla \\ ${ }^{3}$ Junior Resident, Department of Pathology, MKCG MCH, Berhampur
}

\begin{abstract}
Most of the deaths caused by the severe acute respiratory syndrome corona virus 2 (sars-cov-2) is attributable to the high incidence of Acute respiratory distress syndrome (ARDS).The mechanism of ARDS has been debatable, with recent researches postulating an inflammatory induced pro-thrombotic state associated with abnormal lipid generation. Fenofibrate, a widely available low-cost generic drug approved by the FDA, may be beneficial in covid-19 owing to its lipid lowering as well as immunomodulatory effects.

Keywords: Covid-19, ARDS, Fenofibrate.
\end{abstract}

\section{Introduction}

The COVID-19 pandemic has affected millions of people worldwide and has caused over one million deaths. Although most of the patients have a favourable prognosis, few develop pneumonia and severe hypoxaemia eventually leading to ARDS and death.

\section{Pathology of ARDS in COVID-19}

ARDS is a form of lung injury that occurs in response to various predisposing factors. It is characterised by inflammation, increased pulmonary vascular permeability and loss of aerated lung tissue. The diagnosis of ARDS is based upon severe hypoxaemia bilateral radiographic opacities occurring within 7 days of exposure to known predisposing factors ${ }^{1}$.Central to the pathophysiology of ARDS is the presence of fibrin rich exudates (hyaline membranes) due to activation of coagulation and inhibition of fibrinolysis $^{2}$. The COVID-19 virus stimulates the induction of T-cells over-activation leading to excessive release of inflammatory mediators like tumour necrosis factor alpha (TNF-alpha), interleukin-6 (IL-6), IL-8, IL-10 and vascular endothelial growth factor ${ }^{3}$. All these factors contribute to upregulation of procoagulant activities in the alveolar compartment leading to intra-alveolar fibrin deposition and development of ARDS ${ }^{4}$ Levels of D-dimer, a by-product of clot degradation, are significantly increased in patients with ARDS $^{5}$. Recent studies indicate widespread pulmonary vascular thrombosis is a consistent feature of $\mathrm{ARDS}^{6}$. Increased serum levels of Ddimer $^{7}$ and pulmonary vascular endothelialitis, thrombosis and angiogenesis ${ }^{8}$ have been observed in patients with COVID-19.

\section{Role of fenofibrate}

Fenofibrate $^{9}$ is a synthetic phenoxy-isobutyric acid derivative and prodrug with antihyperlipidemic activity. Fenofibrate is hydrolysed 
in vivo to its active metabolite Fenofibric acid that binds to and activates peroxisome proliferator activated receptor alpha (PPAR-alpha),resulting in the activation of lipoprotein lipase and reduction of the production of apoprotein C-III, an inhibitor of lipoprotein lipase activity. Increased lipolysis and a fall in plasma triglycerides lead to increased catabolism of low density lipoprotein (LDL). Activation of PPAR-alpha increases synthesis of apoproteins AI AII and high density lipoprotein (HDL). Overall Fenofibrate reduces total cholesterol, LDL cholesterol, total TG, TG rich VLDL, while increasing HDL Cholesterol.

Apart from this TG lowering action, Fenofibrate has pleiotropic effects such as anti-inflammatory, anti-oxidant and anti-angiogenesis activities. It can downgrade levels of nuclear factor-kappa beta (NF-KB), TNF-alpha, IL-6, vascular adhesion molecules,cyclooxygenase-2, matrix

metalloproteinase, vascular endothelial growth factor- 1 signalling and oxidative stress ${ }^{10}$. All these effects of Fenofibrate may help to reduce the harmful inflammatory responses in the body. Besides that, as Fenofibrate is effective in lowering fibrinogen, it may serve as a highly valuable therapy for patients with severe COVID19 ,especially those suffering from cytokines storm $^{11}$.

One drawback for Fenofibrate is its ability to upregulate the expression of angiotensin converting enzyme-2(ACE2) ${ }^{12}$ 13. Which increases the risk of viral entry to the cells. This problem can be counteracted by addition of chloroquine or hydroxy-chloroquine, as these drugs inhibit the glycosylation of ACE2 and thereby hinders the binding of viral spike protein to ACE2 and prevent viral entry ${ }^{14}$.

\section{Conclusion}

Fenofibrate is a low cost widely available generic drug which seems to have beneficial effects in treatment of COVID-19, particularly its ability to downgrade ARDS. So use of this drug may be extremely helpful at times when the entire scientific community is putting tremendous effort to find ways to alleviate this global Pandemic.

\section{References}

1. Ranieri VM Rubenfeld GD Thompson BT et al. Acute respiratory distress syndrome: the Berlin Definition. JAMA. 2012; 307: 2526-2533

2. Sebag SC Bastarache JA Ware LB Therapeutic modulation of coagulation and fibrinolysis in acute lung injury and the acute respiratory distress syndrome. Curr Pharm Biotechnol. 2011; 12: 1481-1496

3. Mehta P, McAuley DF, Brown M, et al. COVID-19: con- sider cytokine storm syndromes and immunosuppression. Lancet. 2020;395(10229):1033-1034.. Epub 2020 Mar 16.

4. Ji HL Zhao R Matalon S Matthay MA, Elevated plasmin(ogen) as a Common Risk Factor for COVID-19 Susceptibility. Physiol Rev. 2020; 100: 1065-1075

5. Prabhakaran P Ware LB White KE Cross MT Matthay MA Olman MA, Elevated levels of plasminogen activator inhibitor-1 in pulmonary edema fluid are associated with mortality in acute lung injury. Am $\mathbf{J}$ Physiol Lung Cell Mol Physiol. 2003; 285: L20-L28

6. Greene R Zapol WM Snider MT et al. Early bedside detection of pulmonary vascular occlusion during acute respiratory failure. Am Rev Respir Dis. 1981; 124: 593-601

7. Dolhnikoff $M$ Duarte-Neto $A N$ de Almeida Monteiro RA et al.Pathological evidence of pulmonary thrombotic phenomena in severe COVID-19.J Thromb Haemost. 2020; 18: 1517-1519

8. Ackermann M Verleden SE Kuehnel M et al.Pulmonary vascular endothelialitis, thrombosis, and angiogenesis in Covid19.N Engl J Med. 2020; 383: 120-128

9. pubchem.nchi.nlm.nih.gov 
10. Prasad GS, Govardhan P, Deepika G, et al. Anti- inflammatory activity of antihyperlipidemic drug, fenofibrate, and its phase-I metabolite fenofibric acid: in silico, in vitro, and in vivo studies. Inflammopharmacology. 2018;26(4):973981.

11. Chan NN, Chow FC. Effects of fenofibrate and gemfibrozil on plasma homocysteine. Lancet. 2001;358(9295):1811.

12. Ibarra-Lara L, Hong E, Soria-Castro E, et al. Clofibrate PPAR $\alpha$ activation reduces oxidative stress and improves ultrastructure and ventricular hemodynamics in no-flow myocardial ischemia. $\mathrm{J}$ Cardiovasc.Pharmacol. 2012;60(4):323334.

13. Vincent MJ, Bergeron E, Benjannet S, et al. Chloroquine is a potent inhibitor of SARS corona- virus infection and spread. Virol J. 2005 Aug 22;2: 69.

14. Pastick KA, Okafor EC, Lofgren SM, et al. Review:hydroxychloroquine and chloroquine for treatment of SARS-CoV-2 (COVID-19). Open Forum Infect Dis. 2020;7(4):ofaa130. 